\title{
Development of nitazoxanide-loaded colon-targeted formulation for intestinal parasitic infections: centre composite design-based optimization and characterization
}

\author{
Charu Bharti ${ }^{1}$, Upendra Nagaich², Jaya Pandey ${ }^{3}$, Suman Jain ${ }^{3}$ and Neha Jain ${ }^{2^{*}}$ (i)
}

\begin{abstract}
Background: The current investigation is focused on the development and characterization of Eudragit S100 coated nitazoxanide-loaded microbeads as colon-targeted system utilizing central composite design (CCD) and desirability function. The study initiated with the selection of a BCS class II drug nitazoxanide and its preformulation screening with excipients, selection of polymer and identification of concentration for CCD, selection of optimized formulation based on desirability function, and in vitro release studies in simulated gastric and colonic media and stability studies. A two-factor, three-level CCD was employed with two independent variables, i.e. X1 (chitosan \% w/v) and X2 (sodium tripolyphosphate \% w/v), and three dependent variables, i.e. Y1 (particle size in micrometres), Y2 (percentage yield) and Y3 (percent entrapment efficiency), were chosen. Additionally, surface morphology, mucoadhesion and in vitro drug release studies were also conducted.
\end{abstract}

Result: Chitosan concentration showing maximum entrapment and optimum particle size was selected to formulate chitosan beads. The polynomial equation and model graphs obtained from the Design-Expert were utilized to examine the effect of independent variables on responses. The effect of formulation composition was found to be significant $\left(p^{<} 0.05\right)$. Based on the desirability function, the optimized formulation was found to have $910.14 \mu \mathrm{m} \pm 1.03$ particle size, $91.84 \% \pm$ 0.64 percentage yield and $84.75 \% \pm 0.38$ entrapment efficiency with a desirability of 0.961 . Furthermore, the formulations were characterized for in vitro drug release in simulated colonic media (2\% rat caecal content) and have shown a sustained release of $\sim 92 \%$ up to $24 \mathrm{~h}$ as compared to in vitro release in simulated gastric fluid.

Conclusion: The possibility of formulation in enhancing percentage yield and entrapment efficiency of nitazoxanide and the utilization of CCD helps to effectively integrate nitazoxanide microbeads into a potential pharmaceutical dosage form for sustained release.

Keywords: Central composite design, Desirability function, 3D surface plots, Simulated colonic media, Eudragit S100, Multiple regression, Contour plots

\footnotetext{
* Correspondence: ngulati88@gmail.com

${ }^{2}$ Centre of Pharmaceutics, Amity Institute of Pharmacy, Amity University,

Noida, UP, India

Full list of author information is available at the end of the article
}

\section{Springer Open}

(c) The Author(s). 2020 Open Access This article is licensed under a Creative Commons Attribution 4.0 International License, which permits use, sharing, adaptation, distribution and reproduction in any medium or format, as long as you give appropriate credit to the original author(s) and the source, provide a link to the Creative Commons licence, and indicate if changes were made. The images or other third party material in this article are included in the article's Creative Commons licence, unless indicated otherwise in a credit line to the material. If material is not included in the article's Creative Commons licence and your intended use is not permitted by statutory regulation or exceeds the permitted use, you will need to obtain permission directly from the copyright holder. To view a copy of this licence, visit http://creativecommons.org/licenses/by/4.0/. 


\section{Background}

As per World Health Organization (WHO) 2020 factsheets, soil-transmitted helminths (STHs) also known as intestinal nematodes or roundworms have triggered high morbidity and obstruction of an individual's well-being by inducing infection in approximately 1.5 billion of population worldwide. Children and pregnant women are the prime host of these infections. As per WHO latest estimates, more than 880 billion children need therapy against these parasites as these infections are common in tropical and sub-tropical areas [1]. The WHO has also released the control interventions centred on the intermittent anthelminthic administration (deworming) to the population at risk, supplemented with improved sanitation [2]. Parasitic infections can be instigated by three kinds of microorganisms: ectoparasites, protozoa and helminths. These are responsible for many ill health conditions, including diarrhoea, gastrointestinal upset, vaginal irritation, joint pain, nervous diseases, immune dysfunction and chronic fatigue. Ascaris lumbricoides, Trichuris trichiura, Necator americanus and Ancylostoma duodenale are the major nematode species which cause STH $[3,4]$. Since many times, two main categories of active molecules, i.e. benzimidazoles and nicotinic acetylcholine receptor agonists, are being utilized for the treatment of parasitic infections. But with time, resistance which has been developed in intestinal nematodes with these drug categories in humans has been reported. Thus, to overcome these STH infections, there is a requisite to discover highly effective new therapies and measures to the existing therapies. Nitazoxanide is a promising alternative for the treatment of intestinal nematode infections [5]. Nitazoxanide (NTZ) is a new antiparasitic agent and, chemically, a nitrothiazolyl salicylamide compound. It is the first antiparasitic agent which shown positive activity against both protozoa and helminths, especially for the intestinal parasitic infection therapy. It is basically used in diarrhoea caused by Giardia lamblia/intestinalis or Cryptosporidium parvum [6]. The main metabolites of nitazoxanide have been identified as deacetyl-NTZ or tizoxanide (TIZ). NTZ has poor water solubility due to which it has low bioavailability, and hence, high doses and frequent dosing are needed for the treatment. It is a class II drug as per the Biopharmaceutical Classification System (BCS). Around two thirds and one third nitazoxanide oral dose is excreted in faeces and in urine, respectively [7].

The oral route of administration has been used for both conventional and novel formulations. An oral controlledrelease formulation should exhibit the following individualities: able to attain optimal therapeutic drug concentration in the plasma with the smallest fluctuation, enhance pharmacotherapy of drugs with short half-life, minimize repeated dosing, reduce the dose-related adverse effects in high dose, and advance therapy, efficacy and safety with improved patient compliance [8]. Furthermore, the colon-targeted formulations should have the capability of drug protection via oral route to the colon, i.e. the dissolution and absorption of drug should occur only in colon; degradation should be prevented $[9,10]$. Currently, the physiological features of colon aid in achieving colonic targeting, viz., colon $\mathrm{pH}$ (6.5-7.5), microbial flora-rich segment, slow peristaltic movement, etc. Exploiting these features of colon, several colon-targeted formulations had been suggested like $\mathrm{pH}$ and timedependent, pressure-controlled and some passive targeting drug delivery systems like enzyme-triggered, prodrug and enzyme-degradable polymer-coated drug delivery systems and complex colon-targeting drug delivery systems [11].

Chitosan, a naturally occurring polysaccharide, is emerging as a promising polymer in the development of novel drug delivery system. It is biocompatible and non-toxic in nature. Chitosan is a weak cationic polysaccharide composed of (a $(1 \rightarrow 4) 2$-amino-2deoxy- $\beta$-D-glucan) which is acquired by chitin alkaline deacetylation [12]. The properties of smart polymers such as biodegradability and bioadhesion are the features of chitosan. Poorly soluble drugs or the drugs readily soluble in acidic medium are the good candidates for being developed as chitosan beads as they have the synergistic characteristics of bioadhesion and floating [13]. The beads function as depot basin which will permit the steady release of minute quantities of active in solution state to the upper part of small intestine resulting in greater and more constant drug blood levels. Microbeads are tiny, solid and free-flowing particulate carriers comprising of dispersed active moieties in solution or crystalline state which allow a sustained release or multiple release profiles of treatment with various active agents without any major side effects [14]. Additionally, the beads maintain functionality under physiological conditions; it can incorporate the drug to deliver locally at high concentration ensuring that therapeutic levels are reached at the target site while reducing the side effects by keeping the systemic concentration low.

In this research, optimization of drug-loaded microbeads was carried out by one of the designs of response surface methodology (RSM), i.e. central composite design (CCD). A two-factor, three-level CCD was chosen as it avoids the usage of complete three-level factorial experiment and provides quadratic and rotatable model for the response variables. CCD also gives an extra benefit with prediction of responses at an additional level ' $\alpha$ ', apart from high, medium and low levels [15]. The $\alpha$ is considered as the distance of axial points from the centre. The present investigation was to design, optimize and characterize nitazoxanide-loaded chitosan microbeads using CCD in terms of responses, viz., particle size, percentage yield and entrapment efficiency. Furthermore, formulations were also evaluated for in vitro drug release in simulated gastric fluid (SGF) and release in the presence of rat ceacal content (simulated colonic media) and stability studies. 


\section{Methods}

Materials

Nitazoxanide was received as a gift sample from IndSwift Ltd., Jammu \& Kashmir, India. Chitosan and sodium tripolyphosphate (NaTPP) were obtained from $\mathrm{CDH}, \mathrm{New}$ Delhi, India. Analytical grade chemicals and reagents were used in the investigation.

\section{Methods}

\section{Preformulation studies}

Prior to the development of microbeads, the physicochemical properties of drug, i.e. nitazoxanide, were studied via several significant parameters, viz., organoleptic evaluation (color, odor and texture), melting point range (digital melting point apparatus), ultraviolet-visible (UV) spectroscopy and drug-excipient compatibility studies (Fourier transform-infrared spectroscopy). A standard solution $(1 \mu \mathrm{g} / \mathrm{ml})$ of nitazoxanide was prepared in methanol and scanned by UV-VIS spectrophotometer (Shimadzu UV-1800) between 200 and 800 nm. Furthermore, calibration curve was also plotted by the method suggested by Kapse et al [16]. Nitazoxanide was dissolved in $20 \mathrm{ml}$ of methanol in a volumetric flask and treated with a solution $(10 \mathrm{ml}$ of $5 \mathrm{~N} \mathrm{HCl})$. Different concentrations of chitosan, i.e. $1.5 \% \mathrm{w} / \mathrm{v}, 2 \% \mathrm{w} / \mathrm{v}, 2.5 \%$ $\mathrm{w} / \mathrm{v}, 3 \% \mathrm{w} / \mathrm{v}$ to $3.5 \% \mathrm{w} / \mathrm{v}$, in $1 \% \mathrm{v} / \mathrm{v}$ glacial acetic acid were taken to form beads with $2.5 \% \mathrm{w} / \mathrm{v}$ sodium tripolyphosphate as crosslinking agent and $1 \mathrm{~g}$ of zinc granules in portion while shaking, kept at room temperature for 1 $\mathrm{h}$, and then filtered through a cotton wool. The residue was washed with a $10 \mathrm{ml}$ portion of methanol three times, and $0.5 \mathrm{ml}$ of $2 \% \mathrm{v} / \mathrm{v}$ para-dimethyl aminobenzaldehyde (PDAB) solution prepared in methanol was added and the volume was made up to $100 \mathrm{ml}$. The final concentration of reduced nitazoxanide was made up to $100 \mu \mathrm{g} / \mathrm{ml}$. From the stock solution, concentrations of 5 to $25 \mu \mathrm{g} / \mathrm{ml}$ were prepared and subjected to measurement via a UV-visible spectrophotometer [16]. FT-IR studies were conducted by storing the drug, excipient and drug-excipient mixture (1:1) for 15 days at room temperature in separate glass vial drug- $\mathrm{KBr}$ pellet, excipient $\mathrm{KBr}$ pellet and drug-excipient- $\mathrm{KBr}$ pellet (1:1) and subjected for scanning from 4000 to $400 \mathrm{~cm}^{-1}$ using FT-IR spectrophotometer in a reflectance mode (Perkin Elmer Spectrum Rx, Serial No. - 79225).

\section{Selection of polymer}

For the development of nitazoxanide microbeads, two polymers based on their mucoadhesive and releasemodifying behaviour were selected from the literatures. Chitosan and alginate are commonly used polymers in modifying the drug release of microbeads. Likewise, different sodium alginate concentrations, i.e. $1.5 \% \mathrm{w} / \mathrm{v}, 2 \%$ $\mathrm{w} / \mathrm{v}, 2.5 \% \mathrm{w} / \mathrm{v}, 3 \% \mathrm{w} / \mathrm{v}$ to $3.5 \% \mathrm{w} / \mathrm{v}$, in distilled water were taken to manufacture beads with $3 \% \mathrm{w} / \mathrm{v}$ anhydrous calcium chloride as crosslinker. The polymer showing maximum entrapment of drug was selected and further subjected to the selection of formulation technique [17] (Gulati et al., 2014). All the readings were taken in triplicate $(n=3)$, and standard deviation (S.D.) was calculated from the average value (mean \pm S.D.)

\section{Selection of formulation technique}

Two techniques were taken, viz., ionotropic gelation and emulsion gelation technique. Maximum entrapment, particle size and the microbead structure (observed by compound microscope) were three the parameters for the selection of technique. Additionally, optimization of concentration of selected polymer and its respective crosslinking agent was carried out based on maximum entrapment of drug and optimum particle size [17]. All the readings were taken in triplicate $(n=3)$, and standard deviation (S.D.) was calculated from the average value (mean \pm S.D.).

\section{Ionotropic gelation technique}

Nitazoxanide-loaded colon-targeted microbeads were prepared by dispersing chitosan $(3 \% \mathrm{w} / \mathrm{v})$ in $1 \% \mathrm{v} / \mathrm{v}$ glacial acetic acid with agitation for $24 \mathrm{~h}$. Nitazoxanide was dissolved in acetone and then gradually added to chitosan solution with stirring. Nitazoxanide-loaded chitosan solution was added dropwise using 20-G hypodermic needle fitted with syringe into $2 \% \mathrm{w} / \mathrm{v}$ sodium tripolyphosphate (NaTPP) solution in deionized water at RT with continuous magnetic stirring at $100 \mathrm{rpm}$. The $\mathrm{pH}$ of the system was kept as slightly acidic, i.e. $5 \pm 1$. After 30 min curing time, the microbeads were filtered and washed with distilled water and dried at room temperature for $24 \mathrm{~h}$ in a desiccator [18].

\section{Emulsion gelation technique}

Different concentrations of sodium alginate $(2.5 \% \mathrm{w} / \mathrm{v}, 3 \% \mathrm{w} /$ $\mathrm{v}, 3.5 \% \mathrm{w} / \mathrm{v}$ ) were prepared separately in distilled water. Nitazoxanide and castor oil were added to the solution. Each mixture (containing nitazoxanide $100 \mathrm{mg}$ and castor oil) was stirred properly to prepare homogenous mixtures. The mixture was extruded, using a 20-G syringe needle into $100 \mathrm{ml}$ calcium chloride solution $(1 \% \mathrm{w} / \mathrm{v})$ using a magnetic stirrer (TANCO) at room temperature and $100 \mathrm{rpm}$ speed. After 30 min curing time, the microbeads were filtered and washed with distilled water and dried at $40{ }^{\circ} \mathrm{C}$ for $12 \mathrm{~h}$.

\section{Coating of microbeads}

The coating of optimized microbead formulation was conducted with Eudragit S100 employing solvent evaporation technique. The formulated beads were dispersed into an acetone-based solution of Eudragit S100 to obtain $5 \%$ of weight gain. By applying vaccum at $300 \mathrm{mg}$ 
$\mathrm{Hg}$ in a rotary evaporator, solvent was evaporated at 50 $\mathrm{rpm}$ and further dried in a desiccator for $12 \mathrm{~h}$ with the aid of a vacuum [19].

\section{Optimization of microbeads: Central Composite Design (CCD)}

For the nitazoxanide-loaded microbead optimization, an orthogonal block, two-factor, three-level CCD was employed (Design-Expert ${ }^{\oplus}$ software, version 12, Stat-Ease, USA). The preferred independent variables were polymer concentration $(\% \mathrm{w} / \mathrm{v})$ and crosslinker concentration $(\% \mathrm{w} / \mathrm{v})$. For each independent variable, the CCD has given two axial points $(-\alpha$ and $+\alpha)$ in addition to low, medium and high as shown in Table 1. The preferred responses were particle size (um), percentage yield (\%) and entrapment efficiency (\%). With the selected aspects, CCD had advocated total 09 runs (04 factorial runs, 04 axial runs and 01 centre run). Nitazoxanideloaded microbeads were formulated, and matching values of responses or variables were entered in the design. Ultimately, to obtain the formulation of maximum desirability, constraints with their relevant importance were applied [20].

\section{Evaluation of nitazoxanide-loaded chitosan microbeads Particle size, percentage yield and entrapment efficiency} For the analysis of microbead particle size, randomly 100 microbeads were selected, and their diameter was analysed using the Medical Pro software with the help of optical microscope. The smear formed by the dispersion of microbeads in liquid paraffin was viewed under compound microscope, and then, the diameter of the particles was noted down [21].

The percentage yield of various formulated microbead formulation was computed using the dried final microbead weight with respect to the primary complete weight of the drug and polymer utilized for microbead formulation [22]. Percentage yield was computed with the help of the following formula:

$$
\begin{aligned}
& \text { Percentage yield }=(\text { practical yield } / \text { theoretical yield }) \\
& \times 100
\end{aligned}
$$

Accurately weighed microbeads $(50 \mathrm{mg})$ were crushed and dissolved in $10 \mathrm{ml}$ methanol, vortexed for $5 \mathrm{~min}$ and filtered through a $0.45-\mu \mathrm{m}$ Whatman filter no. 4 . The filtered samples were added with $0.5 \mathrm{ml}$ of $2 \% \mathrm{v} / \mathrm{v}$ paradimethylaminobenzaldehyde (PDAB) solution prepared in methanol [23]. Then, the solution was heated for 10 minutes at $60-70{ }^{\circ} \mathrm{C}$ temperature on water bath. After cooling, the volume of sample solution was made up to $10 \mathrm{ml}$ by methanol and analysed spectrophotometrically using UV-VIS spectrophotometer (Shimadzu, Japan) at $559 \mathrm{~nm}$. The drug entrapment efficiency (DEE) was computed with the given formula:

\section{\%Drug entrapment efficiency $=$ Actual drug content/Theoretical drug content $\times 100$}

All the readings were taken in triplicate $(n=3)$, and standard deviation (S.D.) was calculated from the average value (mean \pm S.D.).

\section{Surface morphology}

The structural descriptions of the bead's surface such as shape were investigated with the help of scanning electron microscopy (Model-ZEISS EVO50, special edition, Japan) using gold sputter technique. The dried microbead particles were coated to $200 \mathrm{~A}^{\mathrm{o}}$ thickness with gold palladium. The operating parameters were $20 \mathrm{~nm}$ working distance, zero-degree tilt and $15 \mathrm{kV}$ accelerating voltage [22]. Photomicrographs were clicked within a range of $50-5000$ magnifications.

\section{Mucoadhesive testing}

A small intestinal tissue freshly cut was acquired from local slaughterhouse within $1 \mathrm{~h}$ of goat slaughter which was cleansed with washing by isotonic saline solution.

\begin{tabular}{|c|c|c|c|c|c|}
\hline \multirow[b]{2}{*}{ Independent variables } & \multicolumn{5}{|l|}{ Levels } \\
\hline & \multicolumn{2}{|l|}{ Low $(-1)$} & Medium (0) & \multicolumn{2}{|l|}{ High $(+1)$} \\
\hline $\mathrm{X}_{1}=$ chitosan $(\% \mathrm{w} / \mathrm{v})$ & \multicolumn{2}{|l|}{2.75} & 3 & \multicolumn{2}{|l|}{3.25} \\
\hline $\mathrm{X}_{2}=\operatorname{NaTPP}(\% \mathrm{w} / \mathrm{v})$ & \multicolumn{2}{|l|}{1.75} & 2 & \multicolumn{2}{|l|}{2.25} \\
\hline \multicolumn{6}{|c|}{ Constraints applied on dependent variables } \\
\hline & \multicolumn{2}{|c|}{ Independent variables } & \multicolumn{3}{|l|}{ Dependent variables } \\
\hline & $\begin{array}{l}\mathrm{X}_{1}: \text { chitosan } \\
(\% \mathrm{w} / \mathrm{v})\end{array}$ & $\begin{array}{l}X_{2}: \text { NaTPP } \\
(\% \mathrm{w} / \mathrm{v})\end{array}$ & Y1: particle size (um) & Y2: percentage yield (\%) & Y3: entrapment efficiency (\%) \\
\hline Constraints & In range & In range & In range & Maximize & Maximize \\
\hline Importance & +++ & +++ & ++++ & ++++ & ++++ \\
\hline
\end{tabular}

Table 1 Independent variables, dependent variables and constraints for central composite design 
The jejunum was separated and soaked in receptor medium (phosphate buffer, $\mathrm{pH}$ 6.4). Therefore, for experimentation, a piece of the jejunum mucosa $(2 \times 3$ $\mathrm{cm})$ was mounted onto glass slide $(2 \times 1 \mathrm{~cm})$ using thread. An exact weight of microbeads $(50 \mathrm{mg})$ was kept on the mucosal surface [22]. The glass slides were put in the grooves of the USP tablet disintegrating test apparatus, and a regular up and down movement was performed in a beaker holding phosphate-buffered saline $\mathrm{pH}$ 7.4. The beads which stayed on the mucosal surface were totalled at a regular interval for up to $10 \mathrm{~h}$. All the readings were taken in triplicate $(n=3)$, and standard deviation (S.D.) was calculated from the average value (mean \pm S.D.).

Percent Mucoadhesion $=$ Number of beads adhered/ Total number of beads applied $\times 100$

\section{In vitro drug release studies in simulated gastric fluid}

In vitro drug release studies of coated nitazoxanide microbeads (equivalent to $100 \mathrm{mg}$ of nitazoxanide) were performed using USP dissolution test apparatus II (DS 8000 Labindia). The dissolution studies were performed in $900 \mathrm{ml}$ of simulated gastric fluid as dissolution medium, which was stirred at $100 \mathrm{rpm}$ at $37 \pm 0.1{ }^{\circ} \mathrm{C}$ following a $\mathrm{pH}$ progression method, i.e. $\mathrm{pH} 1.2$ for the first $2 \mathrm{~h}$ and $\mathrm{pH} 7.2$ phosphate-buffered solution for the rest of $24 \mathrm{~h}$ studies. Aliquots were withdrawn periodically and replaced with fresh medium to maintain sink condition throughout the period. Samples were withdrawn at predetermined time intervals using a pipette; the tip of which was covered with filter paper to avoid drug particles [24]. The withdrawal samples were treated with $0.5 \mathrm{ml} 2 \% \mathrm{w} / \mathrm{v}$ methanolic solution of paradimethylaminobenzaldehyde (PDAB) solution. All samples were kept for $10 \mathrm{~min}$ at $60-70{ }^{\circ} \mathrm{C}$ temperature on water bath. Nitazoxanide content in the aliquots after that adding of PDAB solution was assayed spectrophotometrically (UV-VIS spectrophotometer) at $559 \mathrm{~nm}$ for all samples. The experiments were done in triplicate ( $n$ $=3$ ), and standard deviation (SD) was calculated from the mean value.

\section{Desirability function approach for optimization}

Derringer and Suich had given a numerical optimization technique which aids to optimize all responses at one time. In this research, a desirability function approach was utilized to optimize all three responses altogether with the help of Design-Expert 12. To each independent variable and response, an aim/constraint is assigned, i.e. minimize, maximize, in range, target and equal to. With individual responses (dependent variables), a desirability function is related which has the value between 0 and 1 . The value 0 is for unanticipated responses, and between
0 and 1 (minimum to most preferred) is for desired response. Hence, to establish the anticipated responses in the design space, desirability function approach is most helpful [25].

\section{Evaluation of optimized formulation}

Based on the desirability function, the optimized formulation (FF1) was selected and prepared. It shows a polymeric concentration of $2.912 \% \mathrm{w} / \mathrm{v}$ and a crosslinking agent concentration of $1.947 \% \mathrm{w} / \mathrm{v}$. It was further evaluated for the abovementioned parameters, viz., particle size, percentage yield and entrapment efficiency. Additionally, it was evaluated for in vitro drug release in SGF and simulated colonic media.

Preparation of rat caecal content (simulated colonic media) Conventional dissolution tests have some limitations, viz., unable to investigate the effect of bacterial flora specifically present in colon on drug formulations. To surmount this drawback, rat caecal contents are utilized as a substitute to dissolution media. This media is also known as simulated colonic media. The investigation was conducted in accordance with the Guidelines of Committee for the Purpose of Control and Supervision of Experiments on Animals (CPCSEA) and approved by the Institutional Animal Ethical Committee (IAEC). Rat caecal content was created by the technique as described by Van Den Mooter et al. [26]. Two rats of constant body weight (150-200 g) with no previous drug therapy were kept on normal diet and were given $1.0 \mathrm{ml}$ of $1 \%$ $\mathrm{w} / \mathrm{v}$ chitosan solution (in $1 \% \mathrm{v} / \mathrm{v}$ glacial acetic acid) via oral route for 7 days. This triggers the induction of specific enzymes in rat colon to digest the chitosan. Thirty minutes before the investigation starts, euthanasia was performed on each rat with their abdomen cut and open. The caecum was located, and both ends were ligated and dissected. Simulated colonic fluid pH 6.8 (bubbled with $\mathrm{CO}_{2}$ ) was used to keep the caecal content $[27,28]$. The caecal contents were separately weighed, merged and appended in buffer to produce $4 \% \mathrm{w} / \mathrm{v}$ final caecal concentration. The media was then sonicated using probe sonicator for $5 \mathrm{~min}$ at $4{ }^{\circ} \mathrm{C}$ to break the bacterial cells. The complete procedure was done in $\mathrm{CO}_{2}$ environment to maintain the anaerobic conditions.

\section{In vitro drug release study in the presence of rat caecal content}

Eudragit S100 coated chitosan microbeads were evaluated for in vitro drug release in rat caecal content in a USP Dissolution Test Apparatus II (DS 8000, Labindia) using $900 \mathrm{ml}$ dissolution medium, at $100 \mathrm{rpm}$ and $37 \pm$ $0.5{ }^{\circ} \mathrm{C}$, maintaining sink condition throughout the study. Drug release rate studies were performed initially in GI fluid for $2 \mathrm{~h}$. From the third hour onwards, the release 
study was performed in simulated colonic fluid containing rat caecal content. The experiment was performed with a continuous supply of carbon dioxide into the dissolution media to simulate the colonic environment [29]. All the readings were taken in triplicate $(n=3)$, and standard deviation (S.D.) was calculated from the average value (mean \pm S.D.).

\section{Stability studies as per ICH guidelines}

The stability study of optimized nitazoxanide beads was carried out at different storage conditions, i.e. refrigerator, room temperature and accelerated temperature and humidity conditions $40 \pm 2{ }^{\circ} \mathrm{C} / 75 \pm 5 \% \mathrm{RH}$ for 60 days [30].

\section{Results}

\section{Preformulation studies}

Nitazoxanide was found to be yellow crystalline powder which revealed melting with decomposition in the range of $199 \pm 1{ }^{\circ} \mathrm{C}$ to $201 \pm 1{ }^{\circ} \mathrm{C}$ as reported, thus indicating purity of sample. The UV spectrum of nitazoxanide showed the absorption maxima at $559 \mathrm{~nm}$ in methanol with further derivatization using $p$-dimethylaminobenzaldehyde (PDAB). Hence, all further UV estimation was done at maximum a wavelength of $559 \mathrm{~nm}$. Calibration curve was plotted with a series of dilutions as shown in Fig. 1. The regressed equation is $y=0.0066 x-0.0068$. The value of $r^{2}$ is close to 1, i.e. 0.9924 . The FT-IR spectra of pure nitazoxanide, chitosan and nitazoxanidechitosan physical mixture (1:1) confirmed the absence of any chemical interaction between them after 15 days of sample storage. The values of functional group reported in samples are compiled in Table 2. For the selection of polymers, two mucoadhesive polymers, viz., chitosan and sodium alginate, were chosen at different concentrations $(1.5,2,2.5,3$, and $3.5 \% \mathrm{w} / \mathrm{v})$, and their effect on DEE was recorded as shown in Fig. 2. From the results, it was found that sodium alginate beads possess DEE in the range of $23.56 \% \pm 0.75$ to $58.99 \% \pm 0.48$, while chitosan microbeads have shown greater DEE in the limits of $50.44 \% \pm 1.23$ to $75.87 \% \pm 0.42$. After the selection of polymer, the best formulation technique was chosen based on DEE and PS. The results demonstrated that emulsion gelation technique produced microbeads larger in size, i.e. $960.74 \mu \mathrm{m} \pm 1.02$ and less drug entrapment, i.e. $58.07 \pm 1.75$ as compared to the beads prepared by ionotropic gelation which are possessing high entrapment, i.e. $71.46 \pm 1.02$, and less particle size, i.e. $719.56 \pm 0.79$ as shown in Fig. 3. Apart from this, emulsion gelation method also results in tailing of microbeads, while ionotropic gelation technique results in discretely round free-flowing microbeads as shown in Fig. 4.

\section{Central Composite Design (CCD) for the optimization of polymeric microbeads}

In this study, CCD was selected to investigate the effect of two independent variables on responses. The constraints and importance of independent variables and responses are mentioned in Table 1. As per CCD, 09 formulations were developed and analysed for their responses, i.e. particle size (Y1), percentage yield (Y2) and entrapment efficiency (Y3). All the values are acquired utilizing Design-Expert 12. A full quadratic equation was applied to all the dependent variables which were significantly tested by ANOVA and multiple correlation coefficient $\left(R^{2}\right)$ test. The model $p$ value was also checked for significance. The value of $R^{2}$ should be close to 1 and helps to determine the extent of variation from the average.

The observed highest and lowest particle size of all formulations varied from $845.45 \pm 0.34 \mu \mathrm{m}$ to $942.06 \pm$ $0.67 \mu \mathrm{m}$. The investigated higher and lower range for percentage yield and entrapment efficiency were obtained to be $78.00 \% \pm 1.04$ to $92.82 \% \pm 1.78$ and $65.23 \pm 0.034$ to $91.87 \pm 0.011 \%$, respectively, as shown in Table 3. The best fit polynomial model for

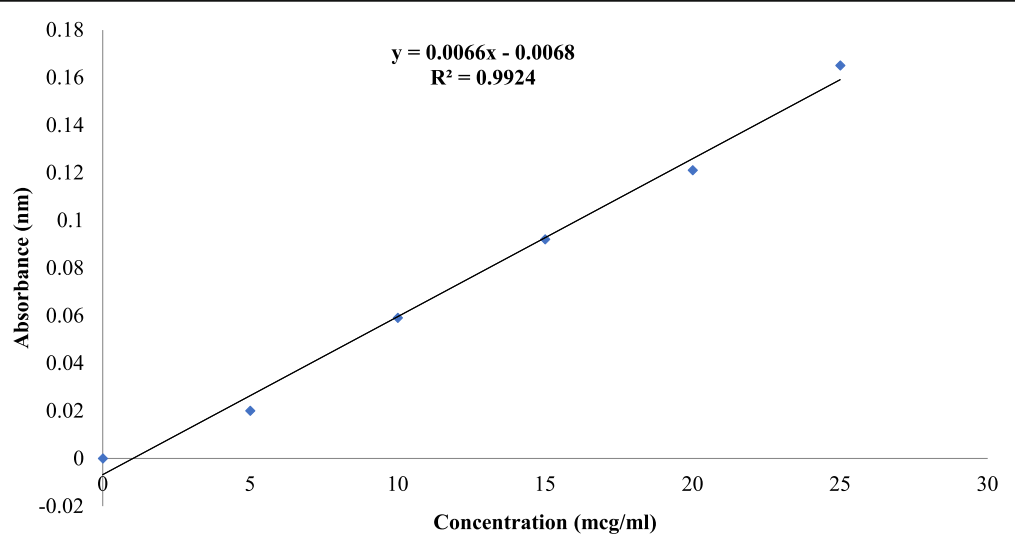

Fig. 1 Calibration curve of nitazoxanide at $559 \mathrm{~nm}$ absorption maxima 
Table 2 Observed wave numbers and the corresponding frequency assignments

\begin{tabular}{|c|c|c|}
\hline S. No. & Frequency assignment & Wave number $\left(\mathrm{cm}^{-1}\right)$ \\
\hline \multicolumn{3}{|c|}{ Observed wavenumbers $\left(\mathrm{cm}^{-1}\right)$ of nitazoxanide } \\
\hline 1 & $-\mathrm{C}=\mathrm{O}$ stretching (amide linkage) & 1662.11 \\
\hline 2 & $-\mathrm{C}=\mathrm{C}-$ ring benzene & 1471.73 \\
\hline 4 & $-\mathrm{CH}$ aromatic ring & 3087.92 \\
\hline 5 & $-\mathrm{C}=\mathrm{O}$ stretching (ester linkage) & 1772.27 \\
\hline 6 & $-\mathrm{N}-\mathrm{H}$ stretching & 3356.15 \\
\hline \multicolumn{3}{|c|}{ Observed wavenumbers $\left(\mathrm{cm}^{-1}\right)$ of chitosan } \\
\hline 7 & -OH stretching & 3460.81 \\
\hline 8 & Symmetric $\left(\mathrm{CH}_{3}\right)$ stretching and asymmetric $\left(\mathrm{CH}_{2}\right)$ stretching & 2927.94 \\
\hline 9 & Amide II band and amide I band & 1600 and 1650 \\
\hline 10 & $\mathrm{C}=\mathrm{O}$ stretching in $\mathrm{NHCOCH}_{3}$ group & 1662.39 \\
\hline \multicolumn{3}{|c|}{ Observed wavenumbers $\left(\mathrm{cm}^{-1}\right)$ of drug: polymer (1:1) physical mixture after 15 days } \\
\hline 11 & $-\mathrm{C}=\mathrm{O}-\mathrm{N}$ stretching & 1662.75 \\
\hline 12 & $-\mathrm{C}=\mathrm{C}-$ ring benzene & 1473.77 \\
\hline 13 & $-\mathrm{C}-\mathrm{H}$ aromatic ring & 3088.32 \\
\hline 14 & $\mathrm{C}=\mathrm{O}$ stretching & 1773.37 \\
\hline 15 & $-\mathrm{N}-\mathrm{H}$ stretching & 3358.30 \\
\hline
\end{tabular}

all three responses, viz., particle size (Y1), percentage yield (Y2) and entrapment efficiency (Y3), was found to be quadratic ( $p$ value $<0.005$ ) as mentioned in Table 4. The variance between "Adjusted $R^{2 \text { " and }}$

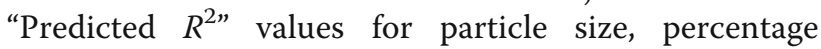
yield and entrapment efficiency were less than 0.2 .

\section{Effect of independent variables on particle size}

The results of observed responses and predicted responses for $Y_{1}$ are mentioned in Table 3. Based on CCD, the combinations of independent factors, i.e. chitosan
$\left(\mathrm{X}_{1}\right)$ and sodium tripolyphosphate $\left(\mathrm{X}_{2}\right)$, for response $\left(\mathrm{Y}_{1}\right)$ resulted in a mathematical relationship in the form of polynomial equation as mentioned below:

$$
\begin{array}{r}
\text { Particle size }\left(\mathrm{Y}_{1}\right)=892.98+57.91 \mathrm{X}_{1}+-28.93 \mathrm{X}_{2} \\
+-17.47 \mathrm{X}_{1} \mathrm{X}_{2}+-143.83 \mathrm{X}_{1}{ }^{2} \\
+-5.96 \mathrm{X}_{2}{ }^{2} \ldots \ldots \ldots \ldots \ldots \ldots \text { Coded equation }
\end{array}
$$

The measurable effect of independent variables $\left(\mathrm{X}_{1}\right.$ and $\left.\mathrm{X}_{2}\right)$ and their interactions $\left(\mathrm{X}_{1} \mathrm{X}_{2}\right)$ on the response $\mathrm{Y}_{1}$

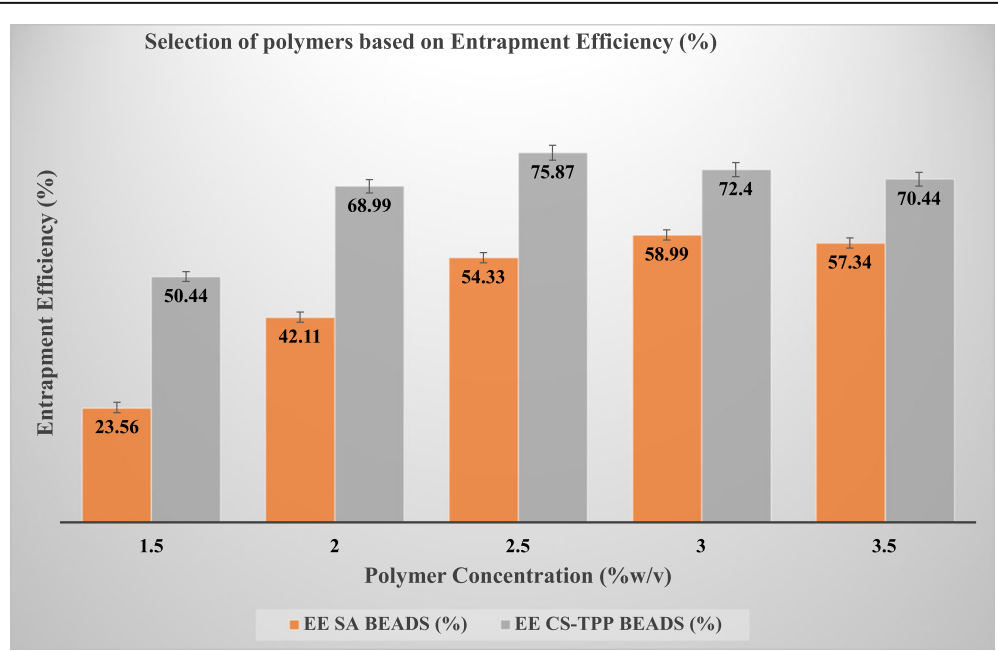

Fig. 2 Selection of polymer based on percent entrapment efficiency 


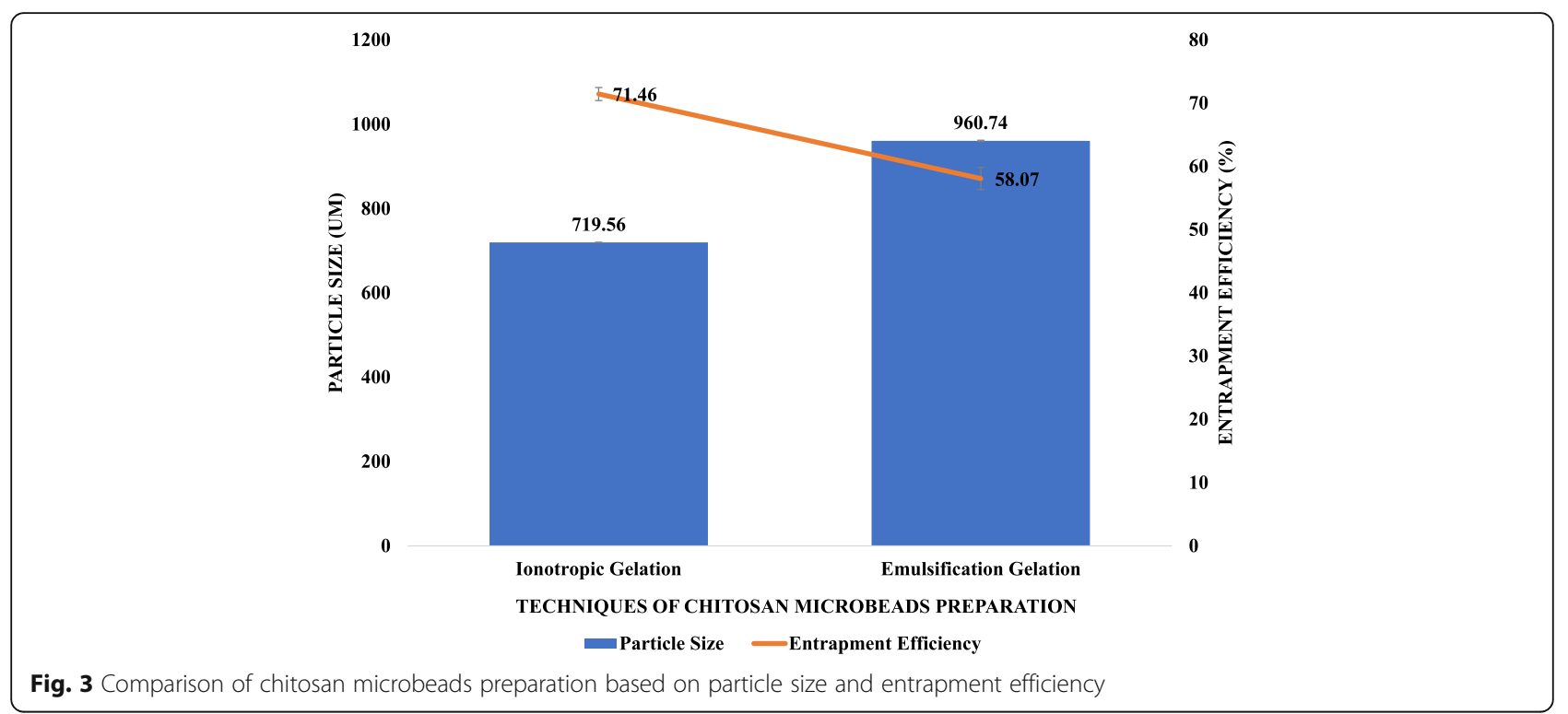

can be noted from the above equation. The value of $p$ ( $^{<}$ 0.05) of coefficients specifies the significance of response as shown in Table 5. The sign and value of coefficients give a direct idea about the nature and extent of effect on responses. If the coefficients of independent variables and their interactions has a positive sign, the effect will be collegial, and if it has a negative sign, the effect will be contrasting. The greater value of factor signifies the considerable influence on the response. Quadratic model was applied to the design. The model effectiveness was confirmed by multiple correlation test $\left(R^{2}\right)$ and ANOVA. The $R^{2}$ value was found to be 0.9985 , and the $p$ value is 0.0001 which confirms the significance of independent variables in response prediction as shown in Table 4. Furthermore, variance inflation factor (VIF) was utilized to interpret multi-collinearity. Here, the value of VIF is 1 which indicates absence of multi-collinearity. The results of particle size are compiled in the form of response plot, contour plot and predicted vs actual plot in Figs. 5, 6 and $7 \mathrm{a}$, respectively. The difference between adjusted $R^{2}(0.9960)$ and predicted $R^{2}(0.9987)$ is less than 0.2 which shows a good fit of the model. The model $F$ value of this model was found to be 398.22 .

\section{Effect of independent variables on percentage yield}

The results of observed responses and predicted responses for $\mathrm{Y}_{2}$ are mentioned in Table 3. The results of percentage yield are expressed in the form of full quadratic polynomial equation given as:

$$
\text { Percentage Yield } \begin{aligned}
\left(\mathrm{Y}_{2}\right) & =83.42+6.88 \mathrm{X}_{1}+1.98 \mathrm{X}_{2} \\
& +-0.0350 \mathrm{X}_{1} \mathrm{X}_{2}+-1.75 \mathrm{X}_{1}{ }^{2} \\
+ & 0.4250 \mathrm{X}_{2}^{2} \ldots . . . \text { Coded equation }
\end{aligned}
$$

This equation exhibited a positive value of both variable coefficients, i.e. $\mathrm{X}_{1}$ (chitosan $\% \mathrm{w} / \mathrm{v}$ ) and $\mathrm{X}_{2}$ (sodium tripolyphosphate $\% \mathrm{w} / \mathrm{v}$ ), but the quantitative effect of $\mathrm{X}_{1}$ is large as compared to $\mathrm{X}_{2}$ as shown in Table 5. This clearly implies that as the concentration of chitosan increases, the percentage also increases. Adjusted $R^{2}$ and predicted $R^{2}$ show a difference less than 0.2 as shown in Table 4. The analysis of this model via ANOVA revealed the $p$ value of less than 0.05 which suggests the

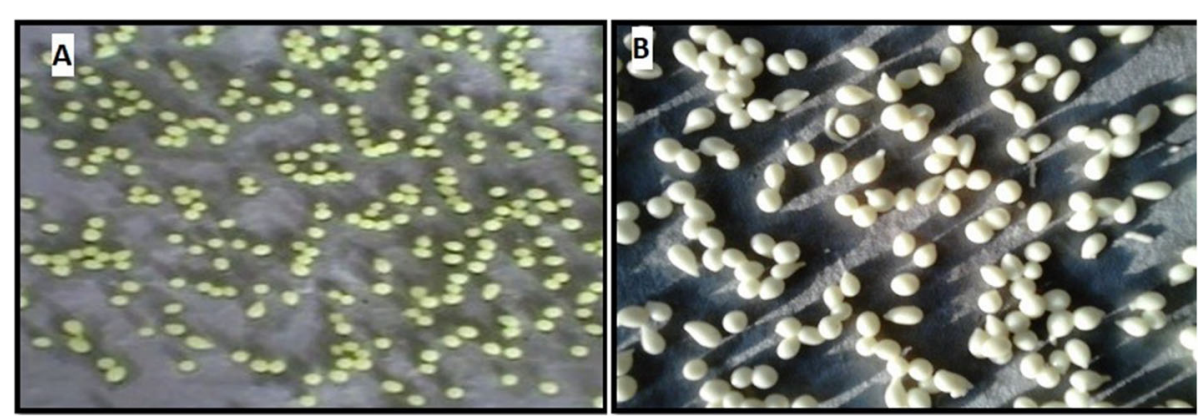

Fig. 4 Lab photographs of nitazoxanide loaded microbeads by a ionotropic gelation and $\mathbf{b}$ emulsion gelation 
Table 3 Experimental and predicted responses of formulations with their coded factors

\begin{tabular}{|c|c|c|c|c|c|c|c|c|}
\hline \multirow[t]{3}{*}{ Formulation code } & \multirow{2}{*}{\multicolumn{2}{|c|}{$\frac{\text { Independent variables }}{\text { Coded factors }}$}} & \multicolumn{6}{|c|}{ Dependent variables } \\
\hline & & & \multicolumn{3}{|c|}{ Observed responses } & \multicolumn{3}{|c|}{ Predicted responses } \\
\hline & $X_{1}$ & $x_{2}$ & $Y_{1}$ & $Y_{2}$ & $\mathrm{Y}_{3}$ & $Y_{1}$ & $Y_{2}$ & $Y_{3}$ \\
\hline \multicolumn{9}{|l|}{ Factorial points } \\
\hline F1 & -1 & -1 & 700.72 & 72.13 & 79.13 & 696.75 & 72.36 & 78.85 \\
\hline F3 & -1 & +1 & 672.87 & 76.13 & 83.12 & 673.83 & 76.38 & 83.48 \\
\hline F7 & +1 & -1 & 848.36 & 86.31 & 82.17 & 847.50 & 86.18 & 81.52 \\
\hline F9 & +1 & +1 & 750.62 & 90.17 & 90.54 & 754.69 & 90.07 & 90.52 \\
\hline \multicolumn{9}{|l|}{ Centre points } \\
\hline F5 & 0 & 0 & 892.78 & 83.17 & 88.67 & 892.98 & 83.42 & 88.09 \\
\hline \multicolumn{9}{|l|}{ Axial points } \\
\hline F2 & -1 & 0 & 688.23 & 75.28 & 81.22 & 691.25 & 74.80 & 81.14 \\
\hline F4 & 0 & -1 & 911.12 & 81.12 & 83.78 & 915.95 & 81.02 & 84.71 \\
\hline F6 & 0 & +1 & 863.12 & 85.13 & 91.87 & 858.09 & 84.98 & 91.53 \\
\hline F8 & +1 & 0 & 810.27 & 88.32 & 85.32 & 807.06 & 88.55 & 85.99 \\
\hline \multicolumn{9}{|c|}{ Optimized nitazoxanide-loaded chitosan microbeads } \\
\hline Optimized nitazoxanide microbeads (FF1) & 3.184 & 2.250 & $829.14 \pm 1.03$ & $90.84 \pm 0.64$ & $89.75 \pm 0.38$ & 809.649 & 89.071 & 91.662 \\
\hline
\end{tabular}

significance of the model applied. F5 exhibited the higher percentage yield (92.82\%). The graphical presentation of effect of independent variables on percentage yield is shown in the form of response plot, contour plot and predicted vs actual plot (Figs. 5, 6 and $7 \mathrm{~b}$, respectively.). Model $F$ value of this model was found to be 356.37 .

Effect of independent variables on entrapment efficiency The results of observed responses and predicted responses are mentioned in Table 3. The full polynomial quadratic equation is shown as:

$$
\begin{aligned}
& \text { Entrapment Efficiency }\left(\mathrm{Y}_{3}\right)=88.09+2.43 \mathrm{X} 1 \\
& +3.41 \mathrm{X} 2+1.09 \mathrm{X} 1 \mathrm{X} 2 \\
& +-4.52 \mathrm{X}_{1}^{2}+0.0317 \mathrm{X}_{2}^{2} \\
& \text { Coded equation }
\end{aligned}
$$

In the above equation, positive values of coefficients of $\mathrm{X}_{1}, \mathrm{X}_{2}$ and their interaction factors symbolize the mutual effect of these variables on response $\left(\mathrm{Y}_{3}\right)$ with significant $p$ values as shown in Table 5 . This reveals that as the polymer and crosslinking agent concentration increases, entrapment efficiency also increases. High concentration of polymer shall entrap the more quantity drug, while the larger concentration of cross-linking agent will prevent drug leakage during formulation. The $p$ value (" $0.05)$ of this model displays significance of the model. The model $F$ value was found to be 37.53 with less than 0.2 difference between adjusted $R^{2}$ and predicted $R^{2}$ value as shown in Table 4 . The results are compiled in the form of contour plot, response plot and predicted vs actual response in Figs. 5, 6 and 7c, respectively.

\section{Surface morphology and mucoadhesion}

The SEM photomicrographs of the drug-loaded microbeads and their surface morphology are shown in Fig. 8. Morphology of the drug-loaded chitosan microbeads was discrete and spherical in shape with a rough outer surface and visible large wrinkles.

The mucoadhesion of all prepared formulations was found to be in the range of $79.09 \pm 0.21$ to $91.23 \pm$ $0.56 \%$ as shown in Fig. 9.

\section{In vitro drug release in simulated gastric fluid and simulated colonic media}

For testing the statistical significance of in vitro drug re-

\begin{tabular}{|c|c|c|c|c|c|c|c|c|}
\hline Response & Model fitting & $R^{2}$ & Adjusted $R^{2}$ & Predicted $R^{2}$ & SD & Model $F$ value & Model $p$ value & $\% \mathrm{CV}$ \\
\hline$Y_{1}$ & Quadratic & 0.9985 & 0.9960 & 0.9817 & 5.84 & 398.22 & 0.0001 & 0.735 \\
\hline$Y_{2}$ & Quadratic & 0.9983 & 0.9955 & 0.9817 & 0.419 & 356.37 & 0.0207 & 0.511 \\
\hline$Y_{3}$ & Quadratic & 0.9843 & 0.9580 & 0.8320 & 0.894 & 37.53 & 0.0131 & 1.05 \\
\hline
\end{tabular}
lease, an ordinary one-way ANOVA was utilized for the comparison of the mean of one column to the mean of

Table 4 Summary of model fitting statistics and analysis of variance (ANOVA) for the responses 
Table 5 Compiled data of coefficients of independent variables and their associated probability $(p)$ value

\begin{tabular}{|c|c|c|c|c|c|c|}
\hline Response & Intercept & A & B & $A B$ & $A^{2}$ & $B^{2}$ \\
\hline Particle size & 892.979 & 57.905 & -28.9317 & -17.4725 & -143.828 & -5.95833 \\
\hline$p$ values & & 0.0002 & 0.0012 & 0.0093 & $<0.0001$ & 0.2445 \\
\hline Percentage yield & 83.4233 & 6.87667 & 1.97833 & -0.035 & -1.75 & -0.425 \\
\hline$p$ values & & $<0.0001$ & 0.0014 & 0.8781 & 0.0097 & 0.2474 \\
\hline Entrapment efficiency & 88.0856 & 2.42667 & 3.40833 & 1.095 & -4.52333 & 0.0316667 \\
\hline$p$ values & & 0.0070 & 0.0026 & 0.0922 & 0.0057 & 0.9633 \\
\hline
\end{tabular}

another column. All formulations revealed an initial burst release as shown in Fig. 10. This may be attributed to the drug leaching from the outer layer of the bead with subsequent entry of dissolution fluid inside the bead matrix resulting in the dissolution and diffusion of the drug. Up to $2 \mathrm{~h}, 22.89 \% \pm 0.14$ to $30.03 \pm 0.18$ release has been observed for all formulations. As the $\mathrm{pH}$ is altered from acidic to alkaline, the release of drug gradually increases. The in vitro release of all formulations was found to be $73.05 \pm 1.09$ to $89.60 \pm 1.10 \%$, respectively. For multiple comparisons, Tukey's test was recommended which was observed to be accurate. ANOVA displays the significant results, but the application of Tukey's test after applying ANOVA reveals where the actual differences lie. Based on the desirability approach, FF1 was formulated and tested for in vitro drug release which shows initial burst release with subsequent sustained release at alkaline $\mathrm{pH}$ up to $86.27 \% \pm 1.02$.

The release of optimized Eudragit S100 coated nitazoxanide microbeads (FF1) was found to be $92.05 \% \pm$ 1.13 in the presence of rat caecal content at $37{ }^{\circ} \mathrm{C} \pm$ 0.015 in $\mathrm{pH} 7.4$ phosphate buffer as compared to without caecal content, i.e. $86.27 \% \pm 1.05$. The comparative drug release is shown in Fig. 11.

\section{Stability studies}

The stability study of optimized formulation (FF1) was carried out at different storage conditions, i.e. refrigerator, room temperature and $40 \pm 2{ }^{\circ} \mathrm{C} / 75 \pm 5 \%$ $\mathrm{RH}$ for 60 days, as shown in Fig. 12. The study displays that the microbeads were stable at refrigeration and room temperature while slight degradation was observed at accelerated conditions, i.e. $40 \pm 2{ }^{\circ} \mathrm{C} / 75 \pm 5 \% \mathrm{RH}$.

\section{Discussion}

Nitazoxanide is a nitrothiazolyl-salicylamide derivative, chiefly comprising of two moieties, i.e. nitrothiazole connected to salicylic acid via peptide bond. When administered orally, its main active metabolite is tizoxanide with a broad spectrum of antihelminthic and antiprotozoal activity. Precisely, it inhibits pyruvate ferredoxin oxidoreductase (PFOR) enzyme-dependent electron transfer reactions which are involved in anaerobic organism metabolism. In the research literatures available, nitazoxanide had been investigated as non-mutagenic, i.e. resistance against this drug can be substantially deferred. It has been established that nitazoxanide is more effective in vitro against both metronidazole-susceptible and metronidazole-resistant strains of Helicobacter pylori and Trichomonas vaginalis [6].

\section{Preformulation studies}

The results of preformulation studies clearly established the quality and the standard of drug, i.e. nitazoxanide. The value of $r^{2}$ is close to 1, i.e. 0.9924, which demonstrates the accuracy of dilutions as shown in Fig. 1. The
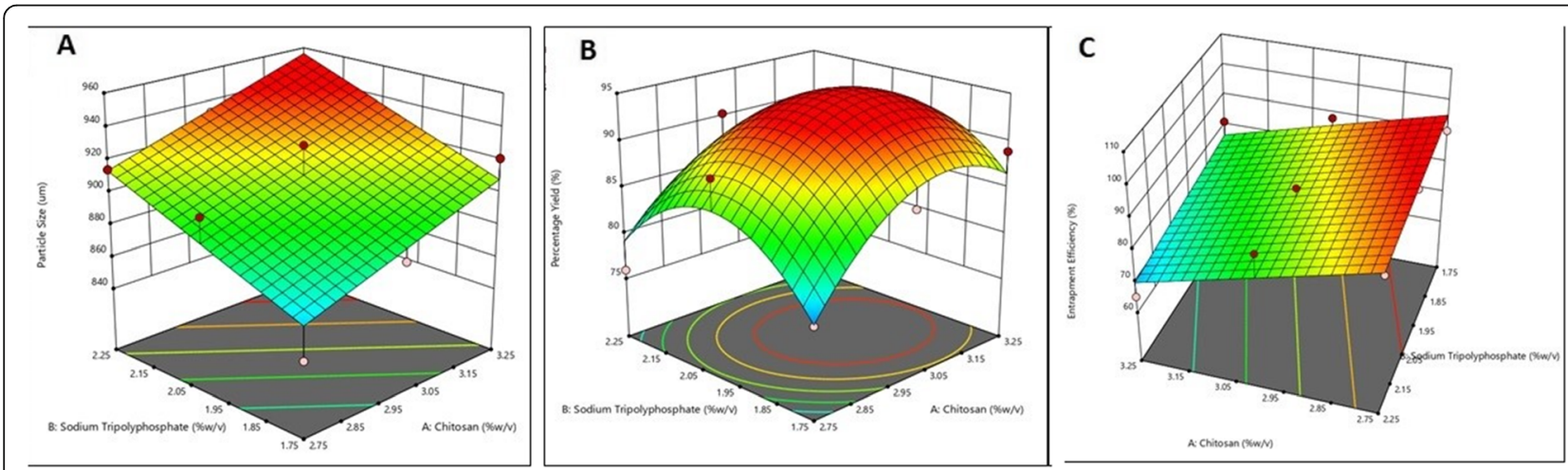

Fig. 5 3D response surface plots illustrating the effect of independent variables for three responses. a For response Y1. b For response Y2. c For response $\mathrm{Y} 3$ 


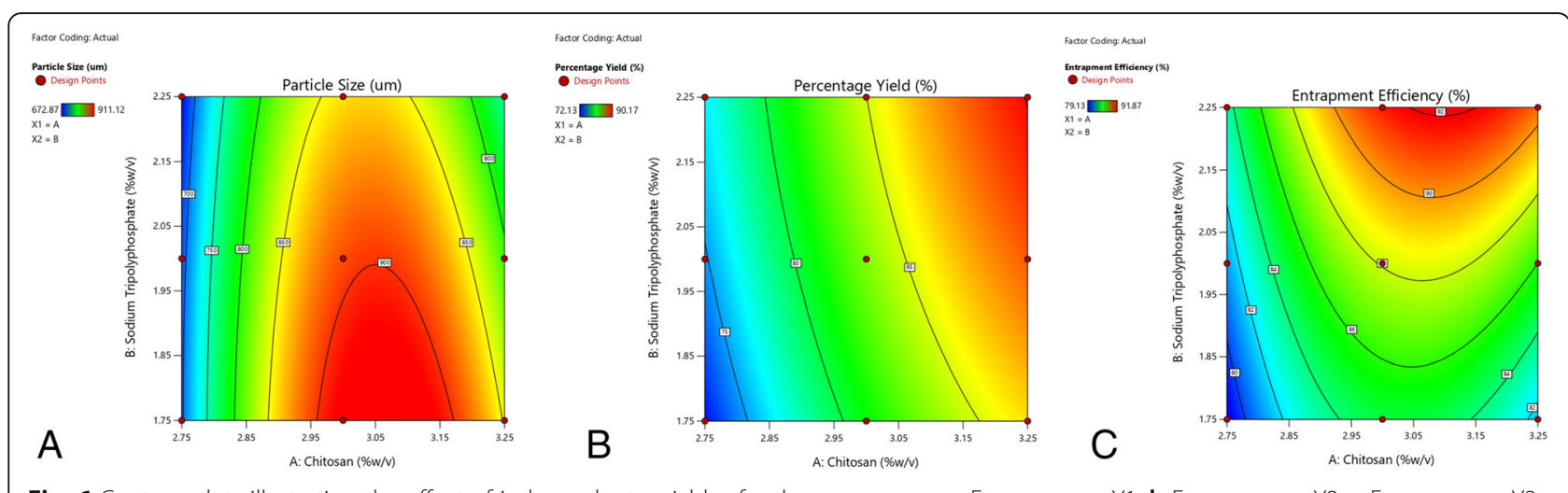

Fig. 6 Contour plots illustrating the effect of independent variables for three responses. a For response Y1. b For response Y2. c For response Y3

FT-IR spectra of pure nitazoxanide, chitosan and nitazoxanide-chitosan physical mixture (1:1) confirmed the absence of any chemical interaction between them after 15 days of sample storage. The values of functional group reported in samples are compiled in Table 2. There is no extra peak observed in the physical mixture of drug and excipient which clears the path for the development of formulation and its characterization.

The selection of polymer for the development of beads is considerable as it forms the matrix for active moiety and hold the drug till its release. Polymer selection was based maximally upon the extent of drug entrapment efficiency (DEE). Two mucoadhesive polymers, viz., chitosan and sodium alginate, were chosen at different concentrations (1.5, $2,2.5,3,3.5 \% \mathrm{w} / \mathrm{v})$, and their effect on DEE was recorded as shown in Fig. 2. From the results, it was found that sodium alginate beads possess smaller DEE as compared to chitosan beads which has greater DEE. The reason attributed for this difference is the basic structure of both linear polysaccharides. In the case of alginate beads, the gel beads are fabricated via sol-to-gel conversion of alginate with the help of divalent cations. Primely, guluronic acid present in alginate forms gel with the cations in the solution which leads to the formation of matrix that has open lattice and porous structure [31]. Thus, alginate beads have low entrapment as compared to chitosan which is a $\mathrm{N}$-deacetylated derivative of chitin. Based on results, chitosan showed higher drug entrapment than sodium alginate microbeads as shown in Fig. 2. After the selection of polymer, the best formulation technique was chosen based on DEE and PS. The results demonstrated that emulsion gelation technique produced microbeads larger in size and less drug entrapment as compared to the beads prepared by ionotropic gelation which are possessing high entrapment and less particle size as shown in Fig. 3. Apart from this, emulsion gelation method results in tailing of microbeads, while ionotropic gelation technique results in discretely round free-flowing microbeads as shown in Fig. 4. Additionally, ionotropic gelation is very ecofriendly and a green process which avoids the usage of surfactants and organic solvents. The higher entrapment of nitazoxanide by ionotropic gelation technique may be due to slightly acidic nature of the system during formulation. It can be hypothesized

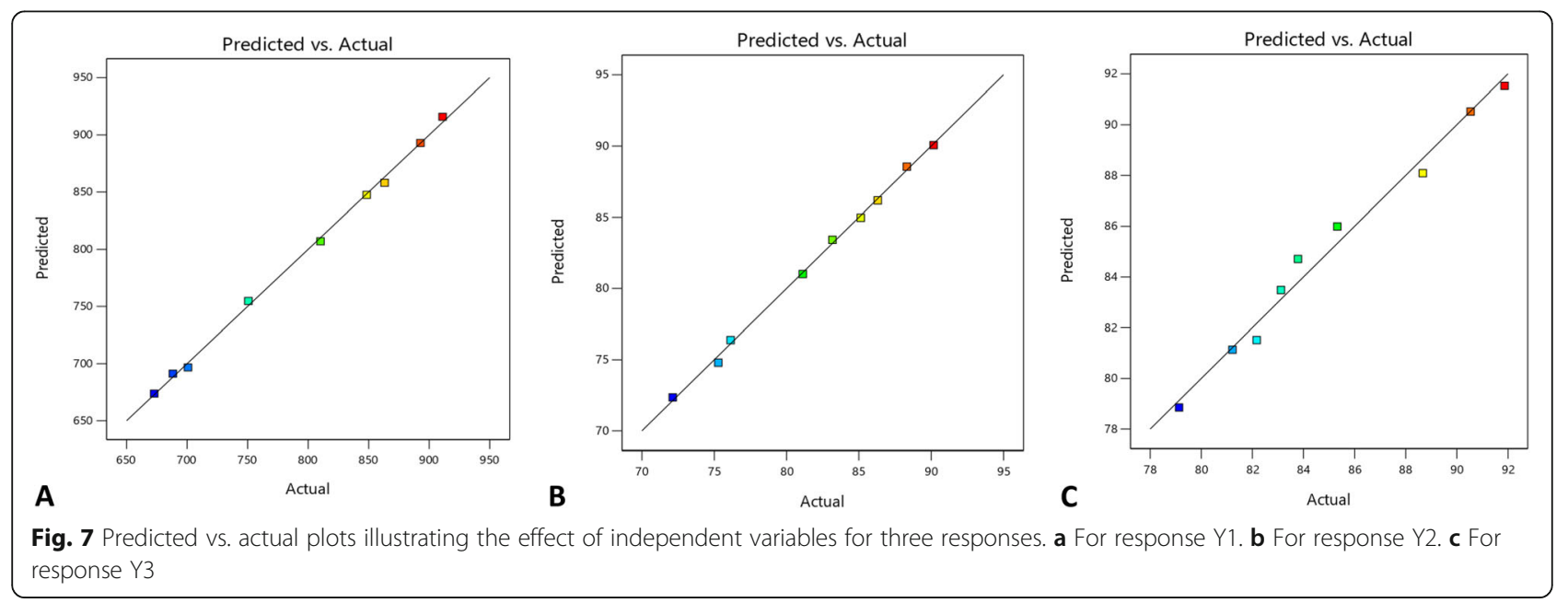




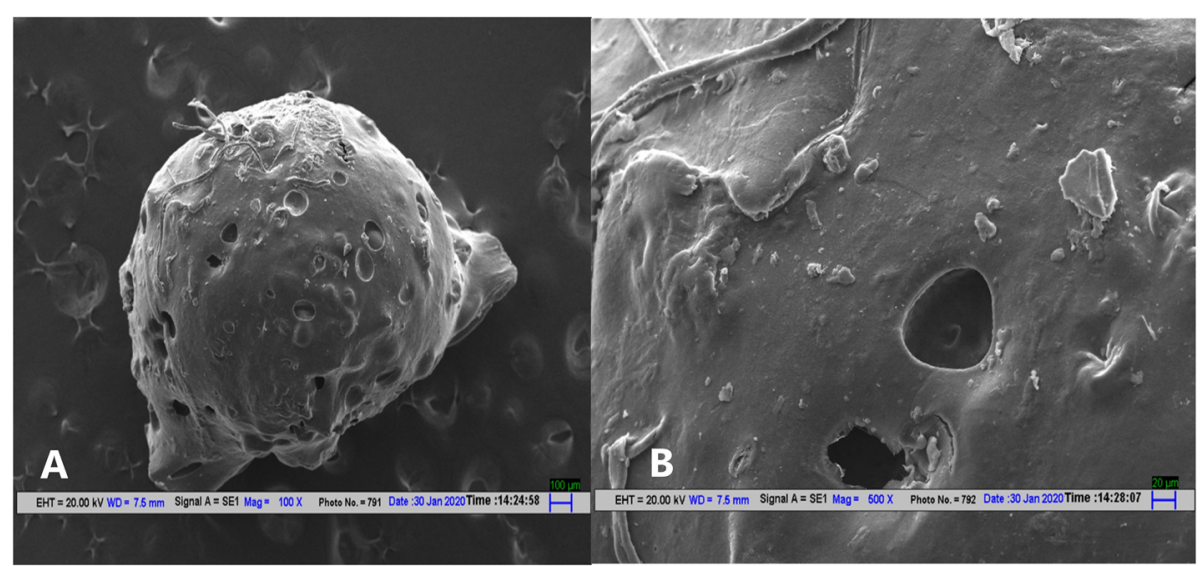

Fig. 8 SEM photomicrograph of nitazoxanide-loaded chitosan microbeads

that at a basic $\mathrm{pH}$ (more $\mathrm{OH}^{-}$ions), there will be a competition for cross-linking between $\mathrm{OH}^{-}$ions and TPP $\mathrm{P}_{3} \mathrm{O}_{10}{ }^{5-}$ ions with the $\mathrm{NH}_{3}{ }^{+}$group of chitosan, while at an acidic $\mathrm{pH}$ (more $\mathrm{H}^{+}$ions), there will be a strong interaction between the $\mathrm{P}_{3} \mathrm{O}_{10}{ }^{5-}$ and $\mathrm{NH}_{3}{ }^{+}$ groups. Hence, more spherical, smaller, stable and homogeneous beads are formed [32, 33]. Consequently, ionotropic gelation technique was selected for the development of nitazoxanide-loaded chitosan microbeads.

\section{Central Composite Design (CCD) for the optimization of polymeric microbeads}

The central composite design (CCD) is a two-factor, three-level design which is desirable since it coerces fewer runs and contains extreme point combination along with points within the design space. Thus, maximum chances are there to obtain relevant and preferred results. Therefore, CCD was selected and employed here to estimate the effect of independent variables, i.e. polymer and cross-linking agent concentration, on three dependent variables, i.e. particle size, percentage yield and entrapment efficiency. As per CCD, 09 formulations were prepared and characterized for responses. Every formulation composition effect was also investigated. The regression calculations generated from the software assist to interpret the type of polynomial model fitting to the preferred responses. The best fit polynomial model for all three responses, viz., particle size (Y1), percentage yield (Y2) and entrapment efficiency (Y3), was found to be quadratic $(p$ value $<0.005)$. The variance between

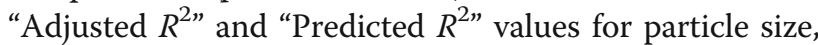
percentage yield and entrapment efficiency were less than 0.2 which reveals the proper fitting of this polynomial model as indicated in Table 4 . Three responses are given in Table 4.

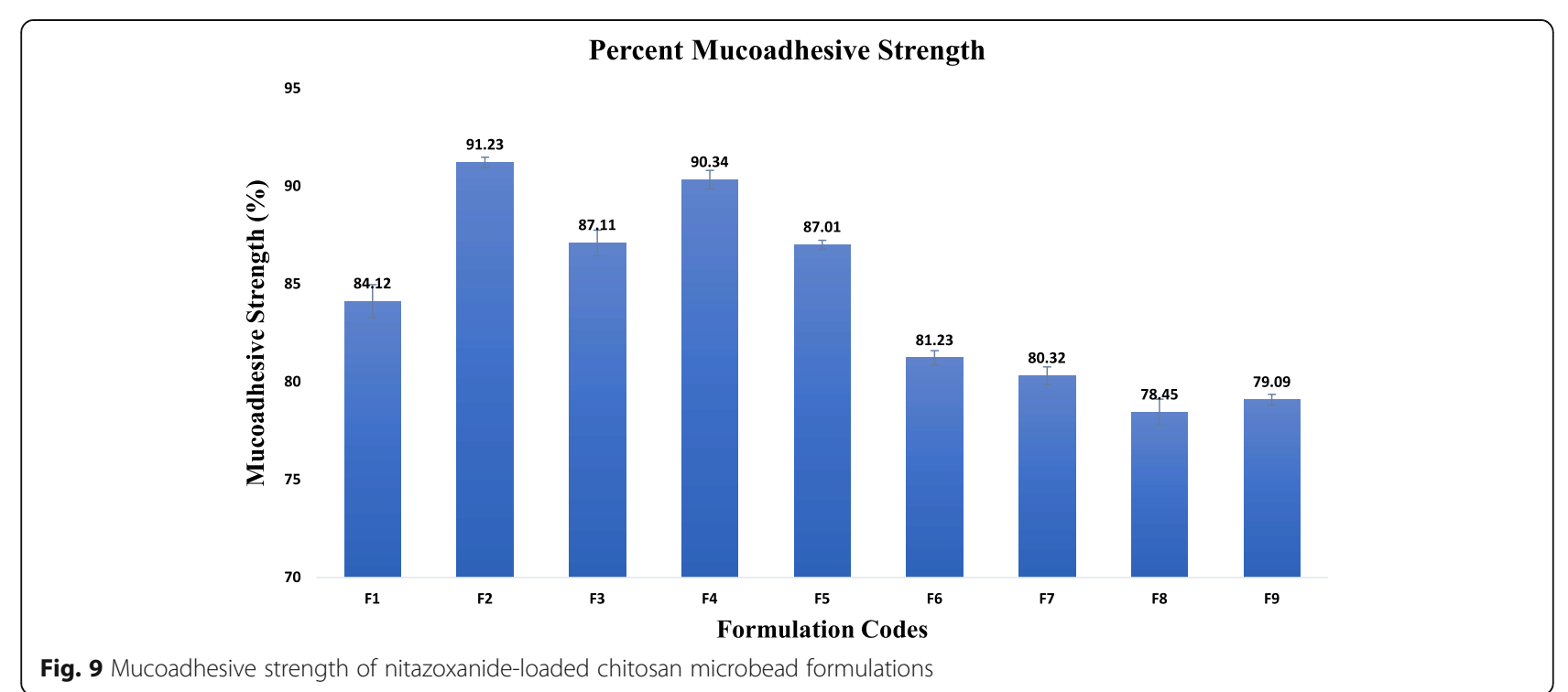




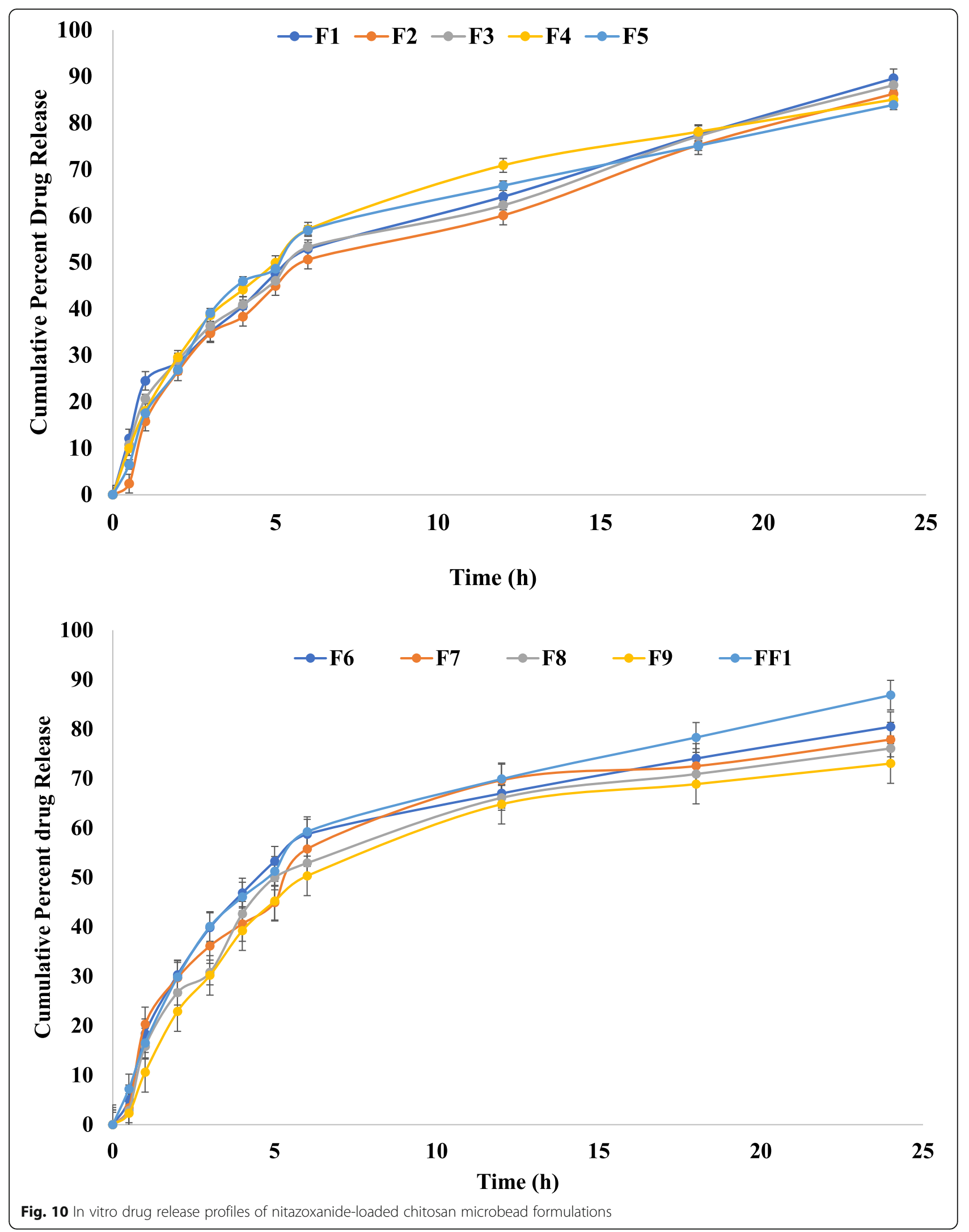




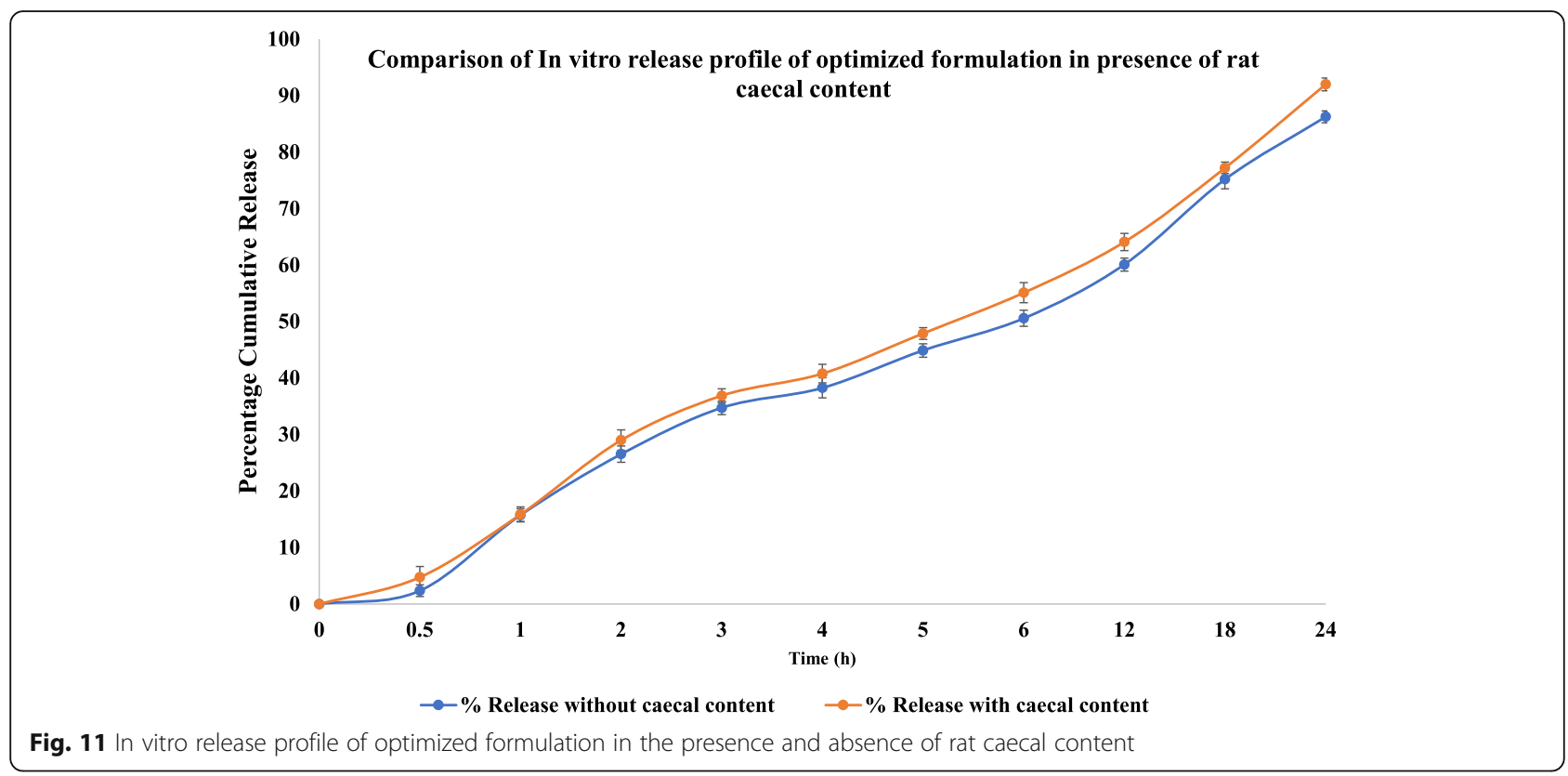

Alteration in the concentration of selected variables effects the particle size of developed formulation as shown in Coded equation (1). The lowest particle size observed was $845.45 \pm 0.34 \mu \mathrm{m}$ for the formulation F1 $(2.75 \% \mathrm{w} / \mathrm{v}$
$\mathrm{X}_{1}$ and $1.75 \% \mathrm{w} / \mathrm{v} \mathrm{X}_{2}$ ), while the highest particle size was observed as $942.06 \pm 0.67 \mu \mathrm{m}$ for the formulation F9 $\left(3.25 \% \mathrm{w} / \mathrm{v} \mathrm{X}_{1}\right.$ and $\left.2.25 \% \mathrm{w} / \mathrm{v} \mathrm{X}_{2}\right)$. From the coded equation 1 and Figs. 5 and 6a, a remarkable increase in

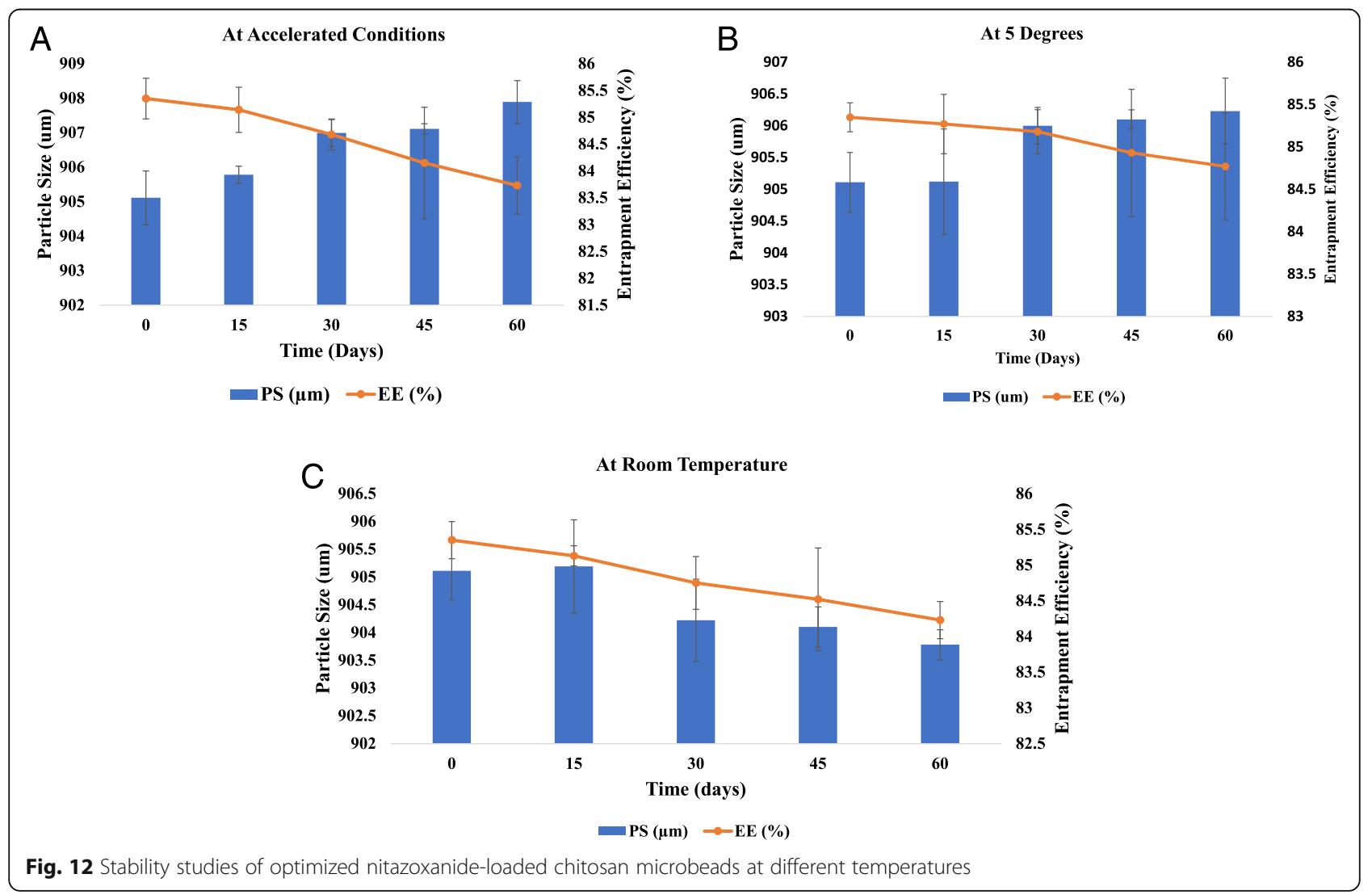


particle size was observed on increasing the polymer concentration. This is a quadratic equation which involves the quantitative effect of independent variables $\left(\mathrm{X}_{1}\right.$ and $\left.\mathrm{X}_{2}\right)$ and their interactions (coefficient with more than one-factor term; $\mathrm{X}_{2}^{2}, \mathrm{X}_{1} \mathrm{X}_{2}$ ) on the response $\mathrm{Y}_{1}$. Herein, $X_{1}$ has a positive coefficient which signifies that as the chitosan concentration increases, the particle size correspondingly upsurges, whereas interaction factors have a negative effect on particle size which can be correlated with the fact that insufficient amount of Na-TPP would be available for cross-linking with increase in chitosan concentration. High polymeric concentration will yield high viscosity solutions due to which cross-linker would be incapable to diffuse into the particles [34, 35]. It can also be observed from Fig. 5a that an increase in polymer concentration leads to increase in particle size up to a specific concentration. Furthermore, the model was verified by ANOVA and multiple correlation test $\left(R^{2}\right)$, and their results are mentioned in Table 4 . The $p$ value and $R^{2}$ value for the Y1 response was found to be $<0.05$ and 0.9985 , respectively, which clearly demonstrates the independent variables had a considerable effect in response estimation. Moreover, the value of variance inflation factor (VIF) is 1 which is used to interpret multi-collinearity of independent factors. The result implies no multicollinearity amongst the independent variables in this quadratic model (VIFs $>1$ indicate multi-collinearity and VIFs less than 10 are tolerable. Likewise, from the coded equation 1 and Table 5 , the value of coefficient of $X_{1}$ has a positive value, indicating its large impact on $Y_{1}$, while a negative coefficient value of $\mathrm{X}_{2}$ indicates its inverse effect on $\mathrm{Y}_{1}$. As per the CCD, the formulation (F5: $3 \% \mathrm{w} / \mathrm{v} \mathrm{X}_{1}$ and $2 \% \mathrm{w} / \mathrm{v} \mathrm{X}_{2}$ ) was very near to optimized formulation.

Percentage yield or product yields are studied to interpret the quantity of excipients utilized to obtain the product. It helps the manufacturer or researcher to closely observe the formulation economically. This dimensionless figure can be used to analyse the exact efficiency of excipients for the development of formulation in terms of improvement of yield, using minimum excipients, reduction of cost and waste [36]. The investigated lower range of percentage yield was found to be $78.00 \%$ \pm 1.04 for the formulation $\mathrm{F} 1\left(2.75 \% \mathrm{w} / \mathrm{v} \mathrm{X}_{1}\right.$ and $1.75 \%$ $\mathrm{w} / \mathrm{v} \mathrm{X}_{2}$ ), while higher range for percentage yield was $92.82 \% \pm 1.78$ for the formulation F5 (3\% w/v X $\mathrm{X}_{1}$ and $2 \%$ w/v $X_{2}$ ). From the coded equation 2 and Figs. 5 and $6 b$, it is established that both $X_{1}$ and $X_{2}$ have positive impact on percentage yield of beads. The result implies that as the concentration of chitosan and tripolyphosphate increases, the product yield also increases. Coded equation 2 showed a perfect fit to the dependent variable/response $\left(\mathrm{Y}_{2}\right)$ as the $\mathrm{R}^{2}(0.9983)$ is in the accordance with the adjusted $R^{2}(0.9955)$. It can also be observed from Fig. $5 \mathrm{~b}$ that an increase in polymer concentration leads to increase in percentage yield. The values of regression analysis of $\mathrm{Y} 2$ illustrated a positive sign for $\mathrm{X}_{1}$ and $\mathrm{X}_{2}$ while a negative sign for interaction factors, i.e. $X_{1} X_{2}$. This suggested that enhancement in chitosan and sodium tripolyphosphate concentration will considerably improve the product percentage yield. The result of $p<$ 0.05 for independent variables after ANOVA (Table 4) analysis reveals significant effect on $\mathrm{Y}_{2}$. F9 possessed a higher percentage yield which supports the above fact.

Entrapment efficiency of microbeads is reliant upon the extent and nature of ionic interaction between chitosan and TPP in terms of charge density and solution $\mathrm{pH}$ [37]. The calculated values of entrapment efficiency were lower $(65.23 \% \pm 0.034)$ for formulation $\mathrm{F} 9(3.25 \% \mathrm{w} / \mathrm{v} \mathrm{X}$ and $\left.2.25 \% \mathrm{w} / \mathrm{v} \mathrm{X}_{2}\right)$ while higher $(91.87 \pm 0.011 \%)$ for formulation F2 $\left(2.75 \% \mathrm{w} / \mathrm{v} \mathrm{X}_{1}\right.$ and $\left.2 \% \mathrm{w} / \mathrm{v} \mathrm{X}_{2}\right)$. Here, interaction factors are also dominant on $\mathrm{Y} 3$ along with $\mathrm{X}_{1}$ and $\mathrm{X}_{2}$. Coded polynomial equation 3 is a quadratic equation which is suitable for the response variable $\mathrm{Y}_{3}$ as the difference between $R^{2}(0.9843)$ and adjusted $R^{2}$ (0.9580) is less than 0.2 as compiled in Table 4. It can also be observed from Fig. 5c that an increase in polymer concentration leads to an increase in entrapment efficiency. The values of regression analysis for $\mathrm{Y}_{3}$ expressed a positive sign for chitosan, sodium tripolyphosphate and their interaction factors. This suggested that the high concentration of chitosan and NaTPP collectively has a synergistic effect on entrapment efficiency. High concentration of polymer and cross-linker will help to accommodate maximum quantity of drug within the polymeric matrix and cross-link tightly to avoid leakage of drug, respectively, in order to give maximum entrapment. Additionally, high TPP concentration increases the cross-linking junction points between TPP polyanion and chitosan.

The SEM photomicrographs of the drug-loaded microbeads and their surface morphology are shown in Fig. 8. Morphology of the drug-loaded chitosan microbeads was discrete and spherical in shape with a rough outer surface and visible large wrinkles.

The mucoadhesion of all prepared formulations was found to be in the range of $79.09 \pm 0.21$ to $91.23 \pm$ $0.56 \%$ as shown in Fig. 9. The in vitro wash-off test showed that as the concentration of chitosan is increased in the formulation, its mucoadhesiveness also increases. But on further increasing the chitosan concentration, the mucoadhesiveness decreases. This may be attributed to the higher concentration of chitosan at which coiling of the polymer molecules may occur, which reduces the flexibility of the polymeric chain, thereby reducing the mucoadhesive strength [22].

The in vitro release of all formulations was found to be in the range of $73.05 \pm 1.09$ to $89.60 \pm 1.10 \%$, respectively, up to $24 \mathrm{~h}$. The dissolution profiles of microbeads are 
shown in Fig. 10. An initial burst release of drug was observed from all the microbead formulations which may be influenced by two reasons: the leaching of drug on the bead outer layer and faster entry of dissolution media inside the bead matrix and subsequent outer diffusion of drug. However, on changing the $\mathrm{pH}$ from acidic to alkaline level, the drug release was slowed down. The $\mathrm{pH}$ responsive release can best be explained based on charge density on the beads, which is an important factor in electrostatic interaction and depends on the $\mathrm{pH}$ of solution [27]. In SGF, protonation of phosphate ions causes hydrogen ions to break, leading to weaker electrostatic interaction. This caused higher swelling and release in $\mathrm{pH} 7.4$ phosphate buffer than acid environment. The optimized formulation was selected and then coated with Eudragit S100 till $5 \%$ of weight gain.

The release of Eudragit S100 coated nitazoxanide microbeads was found to be $92.05 \%$ in the presence of rat caecal content at $37^{\circ} \mathrm{C} \pm 0.015$ in $\mathrm{pH} 7.4$ phosphate buffer as compared to without caecal content. After $2 \mathrm{~h}$, a negligible amount of drug release in acidic environment was observed. The initial release of drug in phosphate buffer was found to be low. The release of drug in $\mathrm{pH} 7.4$ phosphate buffer was very high due to the presence of enzymes. The Eudragit polymer contains carboxyl group; hence, ionization takes place at $\mathrm{pH} 7.4$ due to which membrane coating gets dissolved and beads were exposed to dissolution media following which the polymer matrix swells and erodes releasing entrapped drug [29]. Additionally, eroding of coating membrane may also result due to bacterial presence in the dissolution media. The in vitro cumulative release of microbeads is shown in Fig. 11.

The stability study of optimized batch was carried out at different storage conditions, i.e. refrigerator, room temperature and $40 \pm 2{ }^{\circ} \mathrm{C} / 75 \pm 5 \% \mathrm{RH}$ for 60 days. The study displays that the microbeads were stable at refrigeration and room temperature, while slight degradation was observed at $40 \pm 2{ }^{\circ} \mathrm{C} / 75 \pm 5 \% \mathrm{RH}$. This can be attributed to the fact that at accelerated conditions, chitosan gets degraded as it has the tendency to get swell at high humidity conditions. These stability study data for optimized formulation are given in Fig. 12.

\section{Conclusion}

The developed nitazoxanide-loaded chitosan microbeads were characterized considering every aspect of formulation, and from the results, it is concluded that the coating of chitosan microbeads with Eudragit S100 was efficacious in attaining a sustained release of drug with due course of time in simulated colonic media. Furthermore, CCD is being an efficient tool in the optimization of chitosan beads with minimum number of formulations. This model has adequately predicted the significant responses in terms of particle size, percentage yield and entrapment efficiency. The model graphs (3D surface plot, contour plots and predicted vs actual plots) and polynomial equations were utilized to study the effect of independent variables (polymer and cross-linking agent) on the dependent variables (particle size, percentage yield, entrapment efficiency). From the results, it is evident that independent variables revealed a significant effect on the measured responses $(p<0.05)$. Increase in chitosan concentration increases the particle size and yield but up to a certain level; after that a decrement was observed. The stability data revealed the lowest degradation was observed at $4^{\circ}$ as per ICH guidelines. Thus, nitazoxanide-loaded microbeads can prove to be a potential pharmaceutical dosage form for sustained effect and targeted release.

\section{Abbreviations}

CCD: Central composite design; WHO: World Health Organization; STHs: Soiltransmitted helminths; NTZ: Nitazoxanide; TIZ: Tizoxanide;

BCS: Biopharmaceutical Classification System; FT-IR: Fourier transform-infrared spectroscopy; PDAB: Para-dimethylaminobenzaldehyde; S.D.: Standard deviation; SGF: Simulated gastric fluid; NaTPP: Sodium tripolyphosphate; TPP: Tripolyphosphate; SEM: Scanning electron microscopy; RH: Relative humidity; DEE: Drug entrapment efficiency; PS: Particle size; ANOVA: Analysis of variance; VIF: Variance inflation factor

\section{Acknowledgements}

Not applicable

\section{Authors' contributions}

The authors read and approved the final manuscript. CB: design of work and writing of the original draft. UN: interpretation of data. JN: interpretation of data. SJ: revision of the draft. NJ: conception and design of the work and review and editing of the draft

\section{Funding}

Not applicable

\section{Availability of data and materials}

All data generated or analysed during this study are included in this published article. Any additional data could be available from the corresponding author upon request.

Ethics approval and consent to participate

Not applicable

Consent for publication

Not applicable

Competing interests

The authors report no conflict of interest.

\section{Author details}

${ }^{1}$ Department of Pharmaceutics, School of Pharmacy, Bharat Institute of Technology, By-Pass Road, Meerut, UP 250103, India. ${ }^{2}$ Centre of Pharmaceutics, Amity Institute of Pharmacy, Amity University, Noida, UP, India. ${ }^{3}$ School of Studies in Pharmaceutical Sciences, Jiwaji University, Gwalior, MP 474001, India.

Received: 6 May 2020 Accepted: 20 October 2020

Published online: 10 December 2020

\section{References}

1. World Health Organization UN, Soil-transmitted helminthic infections, < https://www.who.int/en/news-room/fact-sheets/detail/soil-transmittedhelminth-infections>, 2020 (Accessed 04 April 2020). 
2. Taylor-Robinson DC, Maayan N, Donegan S, Chaplin M, Garner P (2019) Public health deworming programmes for soil-transmitted helminths in children living in endemic areas. Cochrane Database Syst Rev 9:CD000371

3. Cappello M (2004) Global health impact of soil-transmitted nematodes. Pediatr Infect Dis J 23:663-664

4. Bethony J, Brooker S, Albonico M, Geiger SM, Loukas A, Diemert D et al (2006) Soil-transmitted helminth infections: ascariasis, trichuriasis, and hookworm. Lancet 367:1521-1532

5. Moser W, Schindler C, Keiser J (2017) Efficacy of recommended drugs against soil transmitted helminths: systematic review and network metaanalysis. BMJ 358:1-10

6. Hemphill A, Mueller J, Esposito M (2006) Nitazoxanide, a broad-spectrum thiazolide anti-infective agent for the treatment of gastrointestinal infections. Expert Opin Pharmacother 7(7):953-964

7. Felix-Sonda BC, Rivera-Islas J, Herrera-Ruiz D, Morales-Rojas H, Hopfl H (2014) Nitazoxanide cocrystals in combination with succinic, glutaric, and 2,5dihydroxybenzoic acid. Cryst Growth Des 14:1086-1102

8. Belali N, Wathoni N, Muchtaridi M (2019) Advances in orally targeted drug delivery to colon. J Adv Pharm Technol Res 10(3):100-106

9. Xu Y, Shrestha N, Preat V, Beloqui A (2020) Overcoming the intestinal barrier: a look into targeting approaches for improved oral drug delivery systems. J. Control Release 322:486-508

10. Lee SH, Bajracharya R, Min JY, Han JW, Park BJ, Han HK (2020) Strategic approaches for colon targeted drug delivery: an overview of recent advancements. Pharmaceutics 12:1-10

11. Cheng H, Huang S, Huang G (2019) Design and application of oral colon administration system. J Enzyme Inhib Med Chem 34(1):1590-1596

12. Garg U, Chauhan S, Nagaich U, Jain N (2019) Current advances in chitosan nanoparticles based drug delivery and targeting. Adv Pharm Bull 9(2):195-204

13. Parhi R (2020) Drug delivery applications of chitin and chitosan: a review. Environ Chem Lett 18:577-594

14. Zhang L, Sang Y, Feng J, Li Z, Zhao A (2016) Polysaccharide-based micro/ nanocarriers for oral colon-targeted drug delivery. J Drug Target 24(7):579-589

15. Ngan CL, Basri M, Lye FF, Masoumi HRF, Tripathy M, Karjiban RA, AbdulMalek E (2014) Comparison of Box-Behnken and central composite designs in optimization of fullerene loaded palm-based nano-emulsions for cosmoceutical application. Ind Crop Prod 59:309-317

16. Kapse GK, Prabhakar G, Raju SA (2006) Spectrophotometric methods for the estimation of nitazoxanide in pharmaceutical formulations. Indian J Pharm Sci 68(3):403-406

17. Gulati N, Nagaich U, Saraf S (2014) Fabrication and in vitro characterization of polymeric nanoparticles for Parkinson's therapy: a novel approach. Braz J Pharm 50(4):869-876

18. Khan MS, Shridhar BK, Srinatha A (2010) Development and evaluation of pH dependent microbeads for colon targeting. Indian J Pharm Sci 72(1):18-23

19. Pandey AK, Choudhary N, Rai VK, Dwivedi H, Kymonil KM, Saraf SA (2012) Fabrication and evaluation of tinidazole microbeads for colon targeting. Asian Pac J Trop Dis 2:S197-S201

20. Gonzalez-Mirza E, Egea M, Souto E, Calpena A, Garcia M (2011) Optimizing flurbiprofen-loaded NLC by central composite factorial design for ocular delivery. Nanotechnology 28:045101

21. Kar NR, Dinda SC (2018) Formulation design and characterization of colontargeted mesalamine microspheres and their biodistribution potential study in mice. Asian J Pharm 12(4):S1481-S1494

22. Malik RK, Malik P, Gulati N, Nagaich U (2013) Fabrication and in vitro evaluation of mucoadhesive ondansetron hydrochloride beads for the management of emesis in chemotherapy. Int J Pharm Investig 3(1):42-46

23. Vino S, Paryani P, Sajitha SL, Ghosh AR (2012) Formulation and evaluation of chitosan beads of levocitrazine dihydrochloride. J Appl Pharm Sci 2(1):221-225

24. Prasad SC, Raj SB, Ajay M, Nagendra BB, Audinarayana N, Reddy KB et al (2011) Formulation and evaluation of lamivudine enclosed alginate microbeads. Pharm Lett 3(6):294-304

25. Derringer G, Suich R (1980) Simultaneous optimization of several response variables. J Qual Technol 12(4):214-219

26. Van den Mooter G, Samyn C, Kinget R (1994) The relation between swelling properties and enzymatic degradation of azo polymers designed for colonspecific drug delivery. Pharm Res 11:1737-1741

27. Kang RK, Mishra N, Rai VK (2020) Guar gum micro-particles for targeted codelivery of doxorubicin and metformin $\mathrm{HCl}$ for improved specificity and efficacy against colon cancer: in vitro and in vivo studies. AAPS Pharm Sci Tech 21:48
28. Niranjan K, Shivapooja A, Muthyala J, Pinakin P (2013) Effect of guar gum and xanthan gum compression coating on release studies of metronidazole in human fecal media for colon targeted drug delivery systems. Asian J Pharm Clin Res 6(2):315-318

29. Venkateshwarlu K, Ravi Shankar K, Ramana Murthy KV, Koteswara Rao GS (2019) Applicability of natural gums for the development of controlled release vancomycin hydrochloride tablets in site specific colon region using statistical optimization. Asian J Pharm Sci 13(4):385

30. Patil A, Pawar P, Gharge V, Doltade U, Doijad R (2018) Mesalamine-loaded mucoadhesive microsphere for colon drug delivery system: effect of process variables and in vitro characterization. Int J Pharma Investig 8:74-82

31. Szekalska M, Puciłowska A, Szymańska E, Ciosek P, Winnicka K (2016) Alginate: current use and future perspectives in pharmaceutical and biomedical applications. Int J Polym Sci:1-18 Article ID 7697031

32. Moeini A, Cimmino A, Poggetto GD, Biase MD, Evidente A, Masi M, Malinconico M (2018) Effect of pH and TPP concentration on chemicophysical properties, release kinetics and antifungal activity of chitosan-TPPungeremine microbeads. Carbohydr Polym 195:631-641

33. Rasala TM, lohiya GK, Kale W, Avari JG (2010) Comparative study of ionotropic gelation technique to entrap diltiazem $\mathrm{HCl}$ in mucoadhesive microparticulate system. J Pharm Res 3(7):1531-1534

34. Ramasamy T, Kandhasami UDS, Ruttala H, Shanmugam S (2011) Formulation and evaluation of xanthan gum based aceclofenac tablets for colon targeted drug delivery. BJPS 47(2):299-311

35. Prasanth AG, Kumar AS, Shruthi BS, Subramanian S (2019) Kinetic study and in vitro drug release studies of nitrendipine loaded arylamide grafted chitosan blend microspheres. Mater Res Express 6:125427

36. Bhumkar DR, Pokharkar VB (2006) Studies on Effect of pH on Cross-linking of chitosan with sodium tripolyphosphate: a technical Note. AAPS Pharm Sci Tech 7(2):E1-E6

37. Abbasalipourkabir R, Fallah M, Sedighi F, Maghsood AH, Javid S (2016) Nanocapsulation of nitazoxanide in solid lipid nanoparticles as a new drug delivery system and in vitro release study. J Biological Sci 16:120-127

\section{Publisher's Note}

Springer Nature remains neutral with regard to jurisdictional claims in published maps and institutional affiliations.

\section{Submit your manuscript to a SpringerOpen ${ }^{\circ}$ journal and benefit from:}

- Convenient online submission

- Rigorous peer review

- Open access: articles freely available online

High visibility within the field

- Retaining the copyright to your article

Submit your next manuscript at $>$ springeropen.com 